\title{
THE APPLICATION OF COMPUTER IN CONSTRUCTION CONTRACT MANAGEMENT AUTOMATION
}

\author{
Yan-Chyuan Shiau \\ Associate Professor \\ Department of Construction Engineering \\ Chung Hua University
}

\begin{abstract}
Contract Management is an important issue in Construction Industries. We need to exactly discuss every detail, agreement and write them precisely on paper to ensure subcontractors can construct project correctly. In CCMS (Construction Contract Management System), when we key in some necessary information, it can automatically generate the whole contract document. This system can produce contract, constructing explanation, insurance assurance, construction specification, safety assurance, etc. This system includes more then 160 construction specifications which cover most architecture activities. By using this tool we can easily handle construction contract. Since this system has carefully considered each detail, it can prevent mistakes to guarantee the achievement of the project.
\end{abstract}

Keywords: Contract Management, Automation, and Construction Management

\section{INTRODUCTION}

Construction Engineering ususally involves many subcontractors. We must properly deal all relations and clearly define the contents of contract to assure the project can be completed in time. It is a complex and difficult task to handle all details for a project.

The profit in construction market is currently very low in Taiwan architect industry. Therefore we need to manage the project carefully to assure a company can survive in such a difficult environment. We need to control all process, such as to summit a tender, to purchase, and to constrct cautiously to ensure company's operation.

We do not need any kind of contract if both sides can keep their promise. However, the business profit is very limited so a whole package of impartial contract is the necessary formality to protect each other. Most people are constrained by limited human resources, some of them even do not have good office automation. CCMS, a well integrated contracting administrating tool, is a wonderful news to provide the solution to Taiwan construction Industry.[1]

\section{CONTRACT DOCUMENTS}

We need a whole set of contract documents to define the obligation for the project. In Taiwan, the document usually include:[2]
A. Construction Contract.
B. Construction Booklet.
C. Construction Attention.
D. Construction Estimation List.
E. Contract Certification.
F. Construction Workers Insurance Assurance.
G. Project Safe Assurance.

On each document, we define different area of agreements to define how project will be proceeding.

\section{CONSTRUCTION CONTRACT MAN- AGEMENT SYSTEM}

CCMS is a contract management system, which can automatically generate a complete set of contract document after entering some needed information.

\subsection{User Interface}

The CCMS is divided into following areas as following (please see Figure 1):

A. Selection Area

In this area, all activity items are listed systematically and can be selected to generate contract documents.

B. Input Area

From this area, we can key-in data that are used to generate the documents. 
C. Pull-down Menu Area

We can maintain the system and edit frequently used data from this area.

D. Message area

The system will display selected item and some other message input by user in this area.

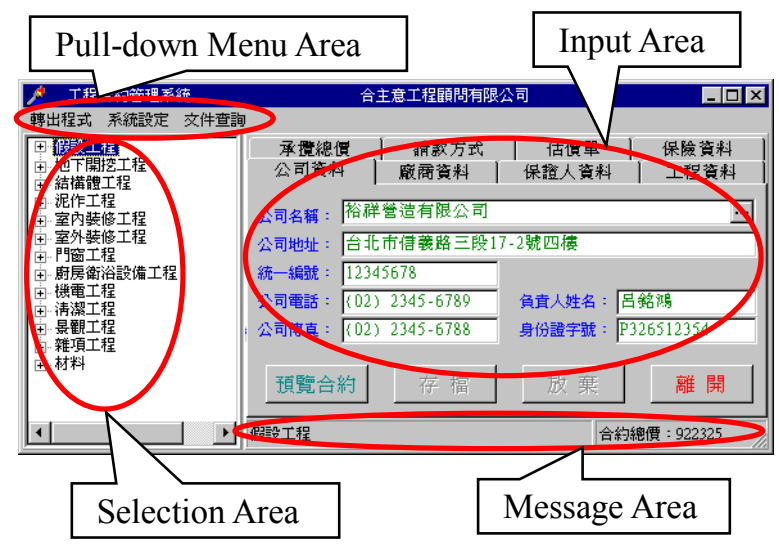

Figure 1. CCMS User Interface

\subsection{Document Categories}

In CCMS, we have collected 160 construction items specification which are divided into 13 categories:

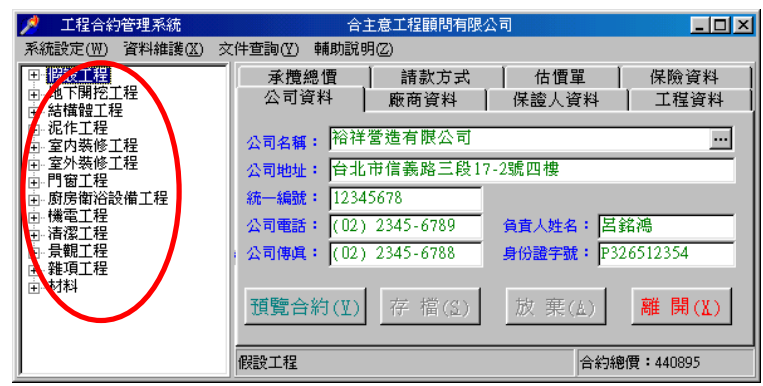

Figure 2. 13 Document Categories
A. Temporary works
B. Underground works.
C. Structure works.
D. Plaster works.
E. Interior decoration works.
F. Outdoor decoration works.
G. Doors and windows works.
H. Kitchen and bathroom facilities.
I. Mechanical equipments.
J. Clean works.
K. Landscaping.
L. Miscellaneous works.
M. Materials

\subsection{System Input Data}

In CCMS, we only need to input following message to produce a contract:

A. Company Information

This includes company name, telephone numbers, address, ID, and the name of the boss.

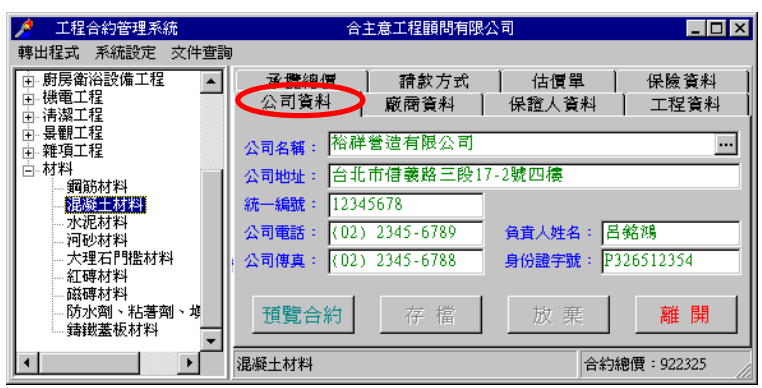

Figure 3. Company Information Input Interface

B. Subcontractor Information

C. Guarantor Information

D. Project Information

This includes project name, location, scope, start date, duration, and govern court.

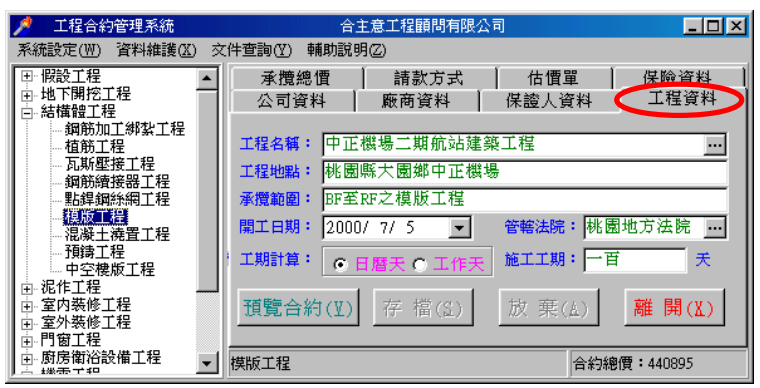

Figure 4. Project Information Input Interface

E. Management Information

This includes tax, maintain period, advance charge, contract signed date, and total price of the contract.

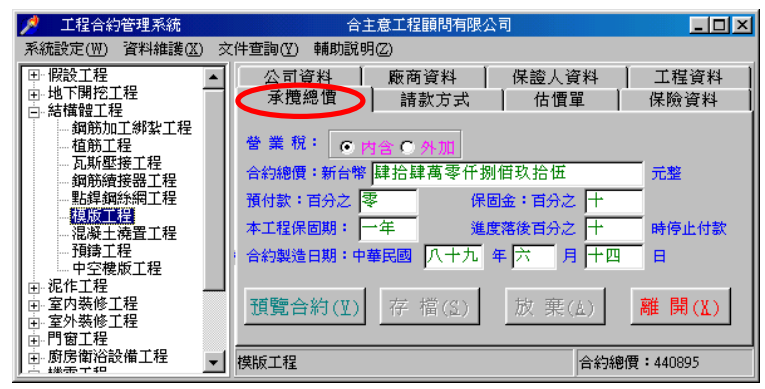

Figure 5. Manage Information Input Interface

F. Requesting Information

This includes request frequency, request date, drawing date, drawing amount, payment style, and drawing money attention. 


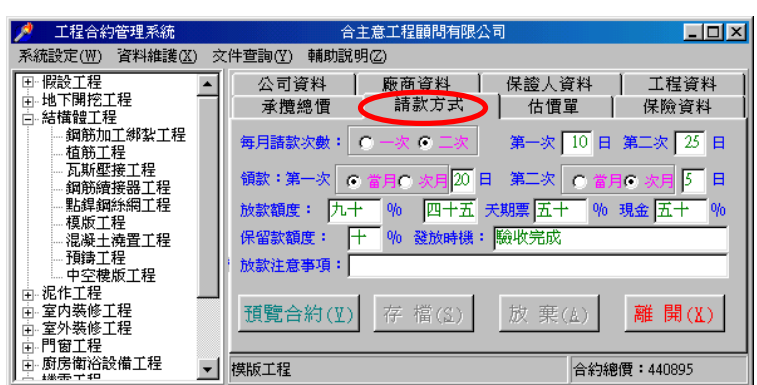

Figure 6. Requesting Information Input Interface

\section{G. Estimation List}

This includes items, unit, unit price, quantity, subtotal and amount.

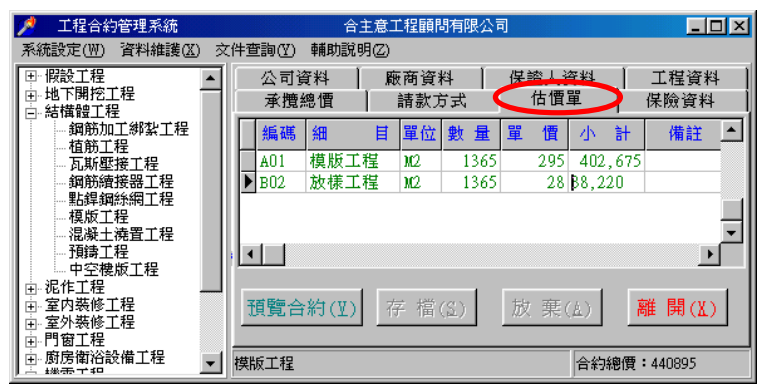

Figure 7. Estimation List Input Interface

H. Insurance Information

This includes insurance company, individual injury payment, maximum individual payment, total responsible amount, and sharing fee of the subcontractor.

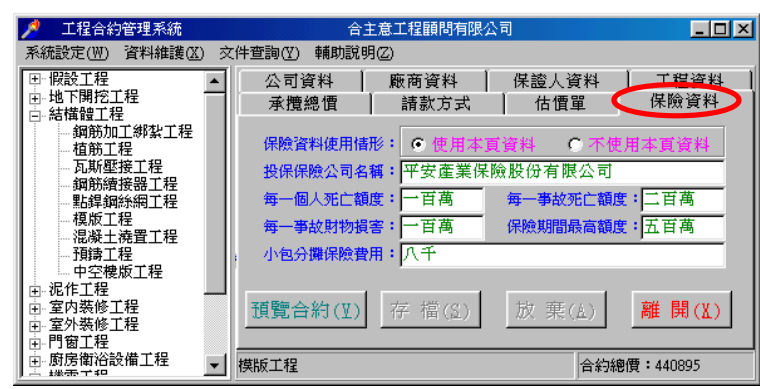

Figure 8. Insurance Information Input Interface

\section{DOCUMENT GENERATING}

When user input all necessary information, save them into system and click "Preview" button, the system will automatically parse all input data and translate them into contract documents. In Figure 9, the Construction Contract is displayed by MS Word, which can be used immediately.

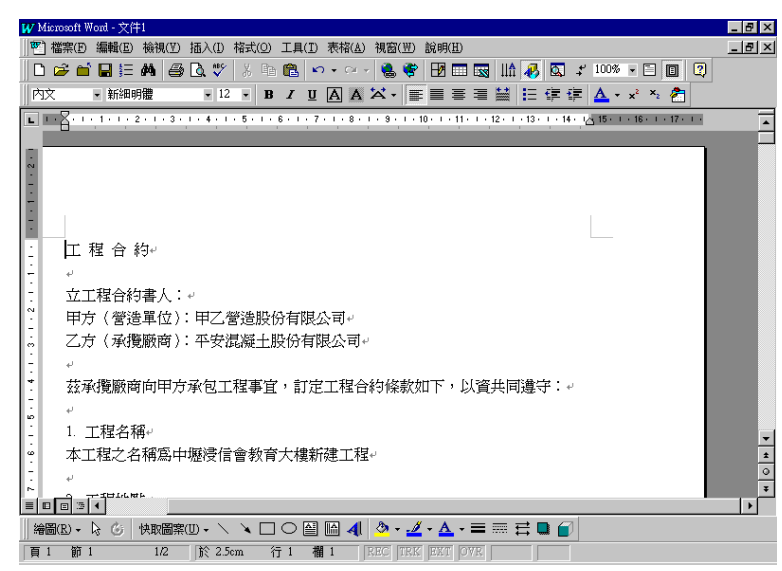

Figure 9. Contract Generated by CCMS

\subsection{Text Substitution}

Most company may have the same documentation format. However, In CCMS we allow users to define their own contract format. There are some files can be modified freely to fit their need:
A. Contract.txt (for Contract.doc)
B. Cover.txt (for Cover.doc)
C. Explain.txt (for Explain.doc)
D. Guarantee.txt (for Guarantee.doc)
E. Insurance.txt (for Insurance.doc)
F. Notification.txt (for Notification.doc)
G. Safety.txt (for Safety.doc)
H. TakeMoney.txt (TakeMoney.doc)

Table 1. Company Information

\begin{tabular}{|l|l|}
\hline Fied name & Related Information \\
\hline CompanyName & Name of the company \\
\hline CompanyAddress & Address of the company \\
\hline CompanyID & The ID of the company \\
\hline CompanyTel & Tel number of the company \\
\hline CompanyFax & Fax number of the company \\
\hline CompanyBossName & Boss name of the company \\
\hline CompanyBossID & Boss ID of the company \\
\hline
\end{tabular}

User can replaced any content on all source data files except some reserved word. However, we can move these words to anywhere to meet our need. These key words listed on Table 1 will be parsed by the system and replaced into the corresponding place in the documents. The data shown in Figure 10 is the original source file. After translation, the generated document is shown in Figure 11.

\subsection{File System}

In CCMS, we handle the generated document by the following hierachy:
A. Company Name
B. Project Name
C. Sub-Contract Name 


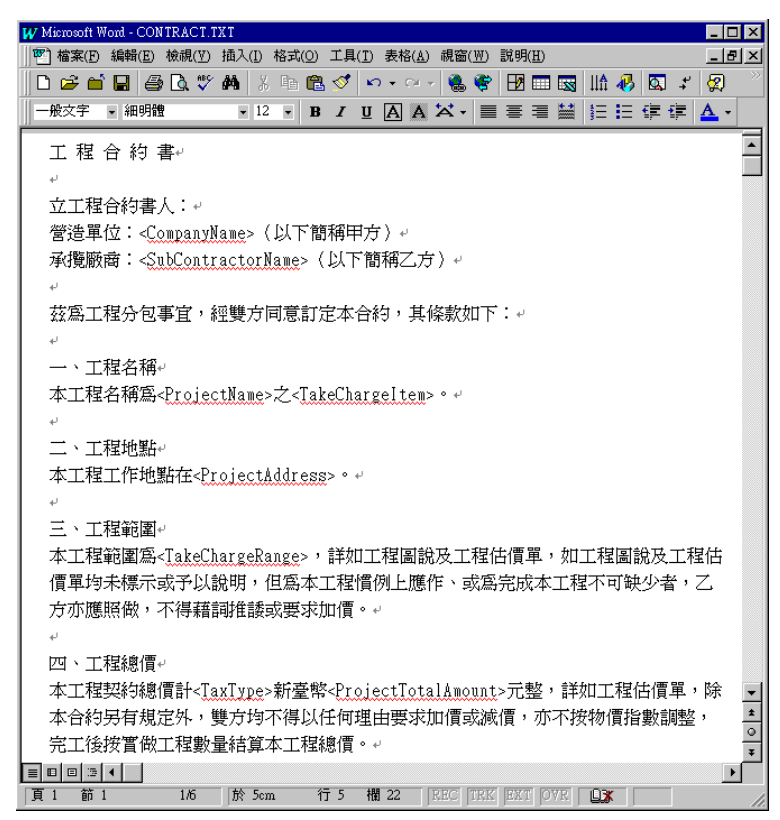

Figure 10. Source Data File Used by CCMS

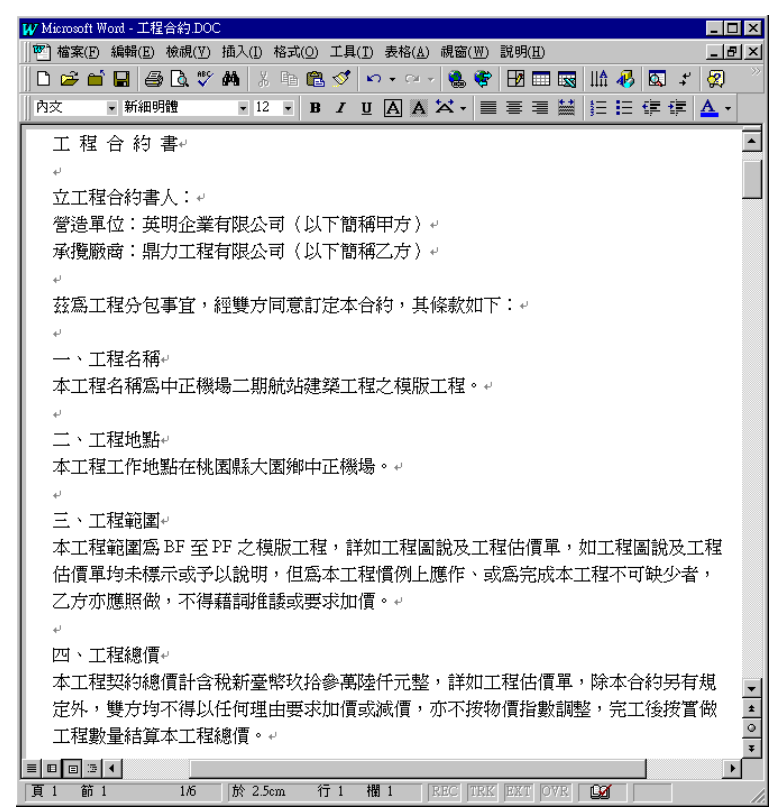

Figure11. Document Generated by CCMS

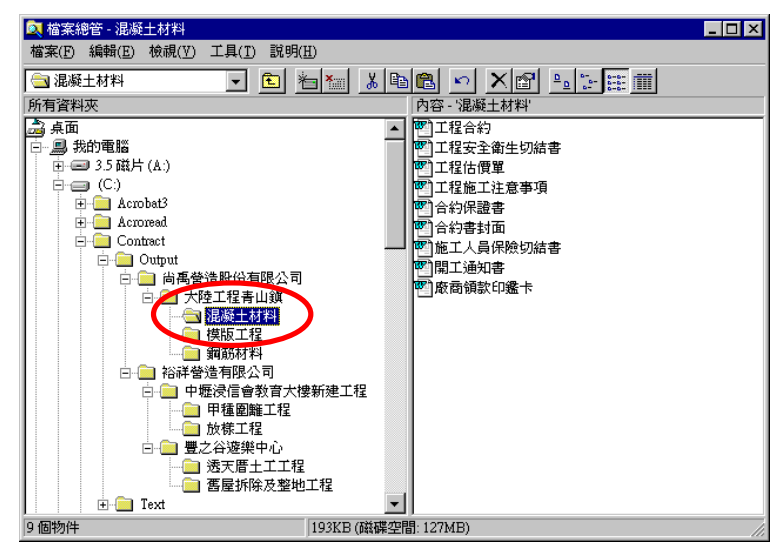

Figure12. File Structure of CCMS

In Figure 12 we can see all documents are systematically arranged under different folders. User can easily manage these documents by check the company name, project name, and the sub-contract name.

\subsection{File Review}

User may need to check the content of a contract generated by CCMS. In this system we can invoke the data tracing function as shown in Figure 13 to display input data of a selected project. The key-in data of the selected project is shown in Figure 14.

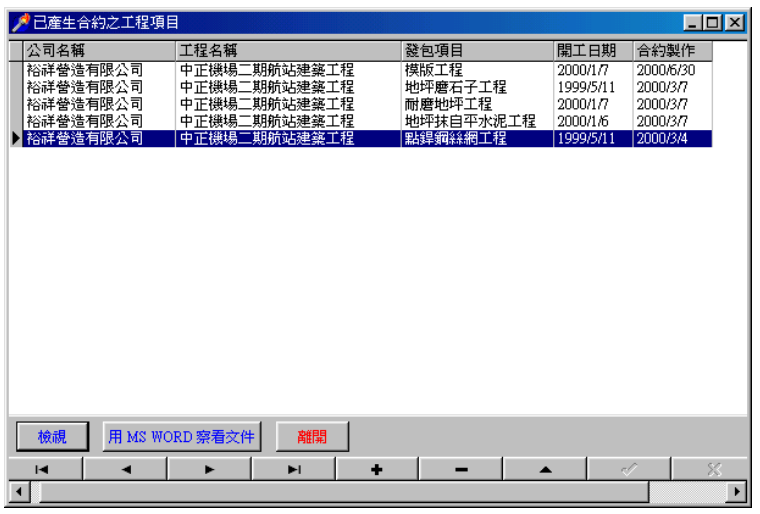

Figure13. Project Selecting Dialogue of CCMS

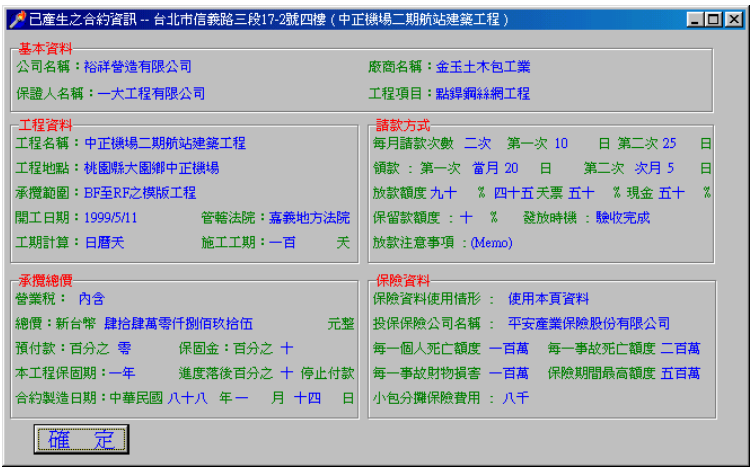

Figure14. Key-in Data of a Selected Project

\section{DISTINGUISHING FUTURE OF CCMS}

There are some distinguishing future of CCMS:

A. Easy to Install

User can follow the install procedures to install the CCMS easily.

B. Easy to Operate

All related information of the company, subcontractor, and guarantors can be stored in the system. User only need to do some simple selection (as shown in Figure 15) can accomplish the data feeding to the system. By using this system, a new user can easily generate complete contract documentation within 10 minutes. 


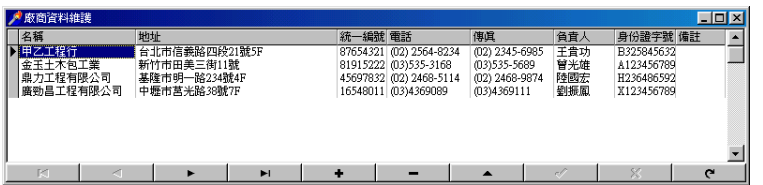

Figure15. Data Selection of CCMS

C. Responsibility Are Well Defined

In CCMS, all duties are clearly written on the documents. This will reduce all possible disputes in construction stage.

D. Construction Principle

In this system, all construction specification is clearly defined on the documents. The new engineers can handle a new item by following the listed focal point.

E. Reduce the Blind Spot

The system has considerate all management details. User will not forget any important element. This can assure the project can be accomplished on time and within the budget.

F. Improve the Operating Physique

This system has made some efforts in rationalization and standardization. This does make a big contribution to the Construction Automation in Taiwan's Construction Industry. This system can also improve the operating physique of a company. It can increase competition of a company.

G. Accumulate Management Capability

Any adjustment can be made on the contract documents directly. All improvement is recorded on the system. This can guide the company to a correct direction. It can also accumulate excellent management science to increase the contention.

H. Flexibility

The output documents can be easily adjusted to fit any specific need.

I. High Accuracy

The system parses the input data and replaced them into correct location. It will reduce any possible mistake within the whole documents.

\section{J. Complete Content}

In CCMS, we have collected more than 160 construction specifications. Construction engineers can use this system to edit a complete set of contract document. [3][4][5][6]

\section{CONCLUSION}

Contract management is an important foundation for construction management. We may suffer unpre- dictable crisis if we do not clearly define the responsibilities for both sides of a construction project. It may take years for a company to accumulate precious resources. However, only a small mistake may consume lots of resource for the firm. For some special situation, a wrong determination may cause an irreversible bankrupt.

We are not to make any unfair contract to strangle subcontractors. However, a set of well-defined contract document is the significant element to keep the company can survive normally. By the help of CCMS, we hope the company can have good administration in contract documents. We hope CCMS can help people to have good automation and computerization in Taiwan's construction industry

\section{REFERENCES}

[1] Yan-Chyuan Shiau, "Engineering Contract Management System", Construction Association, 1998/3.

[2] Yan-Chyuan Shiau, "Contract Management in Construction Industry", Construction Association, 2000/3.

[3]「建築工程施工規範」, 內政部營建署、內 政部建築研究所, 營建雜誌社印, 1997/1。

[4] 吳茂村, 「工程採購發包介面點與成本預算 控制」立基點實業有限公司，1997/9。

[5]「建築工程專業人員訓練教材」，交通部國 工局，1997/9。

[6] 范光懿, 「營造業之成本控制實務」，詹氏 書局，1997/1。 